\title{
REGRAS MORAIS VERSUS REGRAS CONVENCIONAIS: O QUE OS PROFESSORES PENSAM SOBRE REGRAS NA ESCOLA
}

Izabella Alvarenga Silva, Lara Cucolicchio Lucatto, Raul Aragão Martins, Luciana Aparecida Nogueira da Cruz

Faculdade de Filosofia e Ciências, Programa de Pós Graduação em Educação, Marília, SP. Email: izabella.silva@gmail.com.

Agencia de fomento: CAPES, FAPERP.

\section{RESUMO}

O desenvolvimento moral infantil, pela sua complexidade, é um dos aspectos menos abordados nas práticas escolares, uma vez que em grande parte das escolas acredita-se que a moralidade seja algo caracterizado apenas pela organização de um conjunto de normas e regras relacionadas à disciplina das crianças. Nesse sentido, o objetivo desse texto é apresentar e analisar o que professores dos anos finais do ensino fundamental pensam sobre as regras no cotidiano escolar. A pesquisa realizada é descritiva, possui abordagem qualitativa e o delineamento metodológico adotado foi o estudo de caso. Os dados foram coletados em uma escola pública a partir de um questionário, que foi respondido por 24 professores. As análises indicam que a maioria dos professores considera o respeito a regra mais importante para o ambiente escolar, no entanto, citam uma regra convencional, a proibição de mascar chiclete, como a principal regra desrespeitada pelos alunos.

Palavras-chave: Escola, professores, regras morais, regras convencionais, respeito.

\section{MORAL RULES VERSUS CONVENTIONAL RULES: WHAT THE TEACHERS THINK ABOUT RULES IN THE SCHOOL}

\begin{abstract}
The child moral development, for its complexity, is one of the least addressed aspects in schools, since in most of them it is believed that morality is featured only by a set of standards and rules organization related to the discipline of the children. In that sense, this objective of this text is to present and analyze what the final years of elementary schools' teachers think about rules on school routine. The research is descriptive, qualitative approach has and the adopted methodological design was a case study. Data were collected in a public school from a questionnaire, which was answered by 24 teachers. The analysis indicate that most teachers regards respect the most important rule in school routine, however, they cite an conventional rule, the chewing gum ban, as the more disrespected rule by the students.
\end{abstract}

Keywords: School, teacher, moral rules, conventional rules, respect. 


\section{INTRODUÇÃO}

A escola, enquanto instituição educativa, é um importante ambiente no qual as crianças estabelecem contato com seu grupo de pares. Além da aprendizagem de conteúdos específicos, organizados no currículo escolar, nesta instituição as crianças constroem grande parte de seu repertório social, também aprende e organiza internamente as normas morais.

A partir da educação infantil, já é possível, e necessário, que as crianças percebam seus sentimentos e direitos, e também os dos outros, possibilitando, assim, atitudes favoráveis à solução pacífica diante de situações divergentes, conciliando os interesses de todos os envolvidos (SILVA et al., 2015). A importância do trabalho com questões éticas e morais dentro da escola é evidenciada por diversos estudos, tanto no Brasil quanto em outros países (MENIN, 2002; VINHA, 2000; DE VRIES, ZAN, 1998).

O desenvolvimento moral infantil, pela sua complexidade, é um dos aspectos menos abordados nas práticas escolares, uma vez que em grande parte das escolas os professores acreditam que a moralidade seja algo caracterizado apenas pela organização de um conjunto de normas e regras relacionadas à disciplina e ao controle do comportamento das crianças. Tal controle se materializa de diferentes formas, seja por câmeras de vídeos, livros para registro de queixas, punições e criação de inúmeras regras.

No livro O juízo moral na criança Piaget (1932/1994) apresentou seu desejo de compreender como as crianças raciocinam sobre os deveres morais e quais ideias possuem sobre a mentira, a justiça e o respeito, o que para esse autor "constitui o sentimento fundamental que possibilita a aquisição de noções morais" (PIAGET, 1996, p. 4). Ao examinar a relação da criança com as regras das brincadeiras, ele descobriu que existem dois tipos de respeito, o unilateral, caracterizado por práticas de coação, no qual a obediência à regra se sustenta pelo medo da punição, e o respeito mútuo, experimentado nas relações de cooperação entre indivíduos que se enxergam como iguais.

Seguidor da teoria de Piaget, Turiel (1983) define que a estruturação do mundo social pela criança acontece em torno de três categorias: domínio psicológico, domínio social e domínio moral. De acordo com Martins (1995, p. 203), o domínio social possui como base as convenções, que "são uniformidades comportamentais que servem para coordenar interações sociais e estão associadas a conteúdos específicos do sistema social", além disso, caracterizam "ações arbitrárias e relativas a sistemas sociais específicos". Já o domínio moral possui como base a moralidade, esta por sua vez "refere-se à prescrição de julgamento de justiça, direitos e bem-estar, isto é, como as pessoas devem relacionar-se umas com as outras". A partir disso, a interação social da criança passa a ser regulada por mandamentos convencionais e mandamentos morais.

Martins (1995) realizou um estudo em que crianças avaliavam histórias que ilustravam transgressões sociais com temas morais (roubar e não agredir) e sócio convencionais (modo de comer e arrumação de material escolar). Seus resultados, corroborados pelas conclusões de Turiel (1983), indicam que as crianças em idade pré escolar consideram transgressões morais como mais graves e mais passíveis de punição do que as transgressões sócio convencionais.

Considerando as ideias apresentadas sobre a importância da escola trabalhar a ética com os alunos, os tipos de respeito e os tipos de regra, o objetivo desse texto é apresentar e analisar brevemente o que 24 professores dos anos finais do ensino fundamental pensam sobre as regras no cotidiano escolar.

\section{METODOLOGIA}

A pesquisa realizada caracteriza-se por ser descritiva e possui abordagem qualitativa (LÜDKE, ANDRÉ, 1986), o delineamento metodológico adotado foi o estudo de caso (ANDRÉ, 1984; YIN, 2001) com um grupo composto por 24 professores dos anos finais do ensino fundamental. Os encontros com o professores aconteceram em uma escola pública municipal localizada em um 
pequeno município do noroeste paulista entre abril de 2015 e maio de 2016 . O principal objetivo foi proporcionar uma intervenção junto aos professores para tomada de consciência do papel desempenhado pela escola no desenvolvimento moral dos alunos e do ambiente sócio moral proporcionado por eles. Tal intervenção aconteceu na perspectiva de uma formação continuada em serviço. Para a coleta dos dados da pesquisa, foram utilizados três instrumentos: questionário, observação e entrevista.

Os dados apresentados e analisados nesse texto são um recorte do contexto mais amplo da pesquisa. A partir do questionário composto por doze questões dissertativas, respondido pelo grupo de professores em maio de 2016, apresentamos os resultados de apenas duas. As questões aqui analisadas buscavam saber dos participantes: a) as principais regras que os alunos não respeitam na escola e b) cite regras importantes para o bom andamento da escola.

As técnicas de estudo aplicadas aos dados apresentados neste texto foram o cálculo de frequência e porcentagem simples (PEREIRA, 1999), e análise de conteúdo (BARDIN, 1979). Esta pesquisa foi submetida ao Comitê de Ética em Pesquisa e recebeu parecer favorável para a sua realização (CAAE: 38224914.6.0000.5406).

\section{RESULTADOS}

Os professores responderam ao questionário com doze questões que buscou evidenciar as concepções sobre o papel da escola e da família no desenvolvimento moral da criança, como o trabalho com regras acontece na escola, formas de lidar com alunos que não respeitam regras e situações de indisciplina.

Em relação às regras que os alunos não respeitam na escola, $45,8 \%$ do grupo, ou seja, 11 professores citaram que os alunos não respeitam a regra que proíbe "mascar chiclete" na sala de aula. Em relação às regras que os professores consideram importantes para o bom andamento da escola, 58,3\% do grupo, ou seja, 14 professores citaram que a principal regra é a do "respeito", seja respeito ao próximo ou respeito aos professores e funcionários.

Tais números são interessantes por dois motivos. O primeiro se relaciona ao fato de que escolas ainda mobilizam alunos e professores, usando tempo e oportunidade de discussão, com regras vazias de conteúdo e sem propósito educativo. O segundo motivo é o fato de um valor moral ser citado como essencial no cotidiano escolar, além disso, a regra do "respeito" indica o que precisa ser melhorado ou trabalhado na convivência entre adultos e crianças.

A primeira questão evidenciou que os alunos descumprem principalmente uma regra convencional - mascar chiclete, ou seja, uma regra que interfere na conduta de um grupo, mas não possui qualquer princípio moral envolvido ou busca a harmonia das pessoas e do bem-estar alheio, como as regras morais. Já a segunda questão evidenciou como um valor moral é solicitado e bem-vindo ao ambiente escolar, como é o caso do respeito.

\section{DISCUSSÃO}

Tognetta (2013, p. 52) nos convida a pensar sobre o que desejamos para nossos alunos e sobre quais são os grandes objetivos da escola. Estes dois pontos se relacionam diretamente com a forma como as pessoas se relacionam dentro da escola, e também com as regras que são valorizadas neste ambiente: "o que temos feito na escola para formar pessoas que pensem a regra em função da dignidade das pessoas ou em função de um princípio maior que não seja apenas a obediência cega e inconsequente?".

Ainda neste mesmo texto, Tognetta (2013) comenta sobre uma pesquisa realizada com professores e alunos sobre a gravidade de algumas ações na escola, os resultados mostram que para os sujeitos investigados as regras estritamente convencionais, como deixar de fazer a tarefa e não usar boné, são tão importantes quanto não bater em alguém, ou seja, as regras convencionais e as regras morais estão no mesmo patamar. 
Tognetta e Vinha (2007) nos dão outros exemplos de regras pelas quais os professores brigam, mas que não influenciam no desenvolvimento da autonomia moral dos alunos, como a proibição de chupar pirulito dentro da sala e a proibição de sair para ir ao banheiro sem a autorização do professor. $\mathrm{O}$ que falta em muitas escolas é que adultos e crianças repensem juntos as regras que organizam o ambiente e são importantes para o bom convívio entre as pessoas. Existem as regras negociáveis e as não negociáveis, e estas devem ser do conhecimento de todos, de forma que seja possível a discussão do porque de determinadas regras, e especialmente dos princípios que sustentam as mesmas.

Em relação ao respeito, eleito por $58,3 \%$ dos professores como uma das regras importantes para o cotidiano escolar, é necessário questionarmos: considerando os dois tipos de respeito apresentado por Piaget (1932/1994), qual tipo de respeito os professores valorizam? o respeito unilateral às figuras de autoridade, que pressupõe a obediência cega das regras e medo de punições, ou o respeito mútuo, que nasce com a cooperação entre os sujeitos a partir de relações democráticas?

É necessário pontuarmos que o respeito é um sentimento moral, não é algo natural, e sim construído nas relações entre as pessoas. Tardeli (2003) conduziu uma pesquisa com professores do ensino médio sobre as concepções do papel do professor, do ponto de vista do respeito. Seus resultados mostram que os professores, ao julgarem uma situação problemática hipotética, consideram a relação professor-aluno a partir de duas categorias, a conversativa, na qual os professores conversam com seus alunos, ou chamam a atenção deles, e a repreensiva, quando os professores tentam eliminar ou impor a solução de um determinado problema ou conflito.

O que podemos supor aqui [...] é que a relação é superficial entre professores e alunos e não se mantém pelo respeito às pessoas. Na categoria Conversativa não se configura de fato o diálogo e nessa categoria Repressiva a autoridade se impõe de fora para dentro, desvinculada de seu efetivo papel (TARDELI, 2003, p. 83).

É comum que os professores, em seus discursos e queixas, demonstrem esperar, ainda que veladamente, uma receita para solucionar o problema de desrespeito pelas autoridades (professores, gestores e pais) dentro da escola, uma vez que existe uma ideia de que o respeito é uma ação traduzida em obediência às regras e comandos.

Os estudos de Piaget (1932/1994) demonstraram que o respeito é um sentimento composto por amor/empatia e medo. Dessa forma, para que o respeito exista, é necessário que exista afeição entre aquele que respeita e o sujeito respeitado, e uma dose de medo, seja ele de punições ou castigos, da perda de admiração ou afeto, ou ainda vergonha de decair aos olhos do outro. Tais características evidenciam que o respeito é um sentimento que demonstra vínculo entre as pessoas. Outro ponto importante é que o respeito é um sentimento que se desenvolve na criança em função da interação que ela estabelece com o meio social.

Considerando o respeito unilateral e as relações de coação, e o respeito mútuo e as relação de cooperação, Piaget (1932/1994) apontou duas tendências morais na criança, a heteronomia e a autonomia. Na moral heterônoma, as regras são impostas e a obediência a elas apoiam-se no medo da punição, na autonomia, as regras passam pela consciência e há reflexão sobre o sentido delas, o respeito às regras passa a ser baseado nas relações de cooperação entre os sujeitos, que se enxergam como iguais.

\section{CONCLUSÃO}

Os dados apresentados anteriormente indicam que os participantes da pesquisa valorizam o respeito como regra essencial no cotidiano escolar. O respeito ao próximo, aos pares e ao 
professor é um sentimento moral, mas será que os professores consideram o respeito mútuo como essencial, ou o respeito unilateral, traduzido em obediência cega?

Uma regra convencional, sem princípios éticos norteadores, foi citada como a principal regra que os alunos não respeitam (mascar chiclete), consumindo tempo e dedicação dos professores. Posto isso, consideramos importante que os profissionais da escola reflitam sobre as regras que devem ser valorizadas e cobradas, ao pensarem em determinada regra deve-se avaliar se vale a pena exigir seu cumprimento e se esta é de fato necessária.

O respeito mútuo, que pressupõe cooperação e relações mais democráticas deve ser encarado como um princípio moral que inspira a discussão e a criação de regras, além de ser o pressuposto inicial das relações interpessoais dentro e fora da escola. A autonomia, intelectual e moral, ainda é um dos grandes objetivos da escola enquanto instituição educativa, no entanto, as dificuldades em esclarecer o que seja a autonomia e qual a melhor forma de promover seu desenvolvimento ainda são um empecilho para que a escola trabalhe a moralidade e a postura ética dos alunos.

\section{REFERÊNCIAS}

ANDRÉ, M. E. D. A. Estudo de caso: seu potencial na Educação. Cadernos de Pesquisa, São Paulo, n. 49, p. 51-54, maio 1984.

BARDIN, L. Análise de conteúdo. Lisboa: Edições 70, 1979.

DEVRIES, R.; ZAN, B. A ética na educação infantil: o ambiente sociomoral na escola. 1. ed. Porto Alegre: Artes Médicas, 1998.

LÜDKE, M.; ANDRÉ, M. E. D. A. Pesquisa em educação: abordagens qualitativas. São Paulo: EPU, 1986.

MARTINS, R. A. Concepções sobre Regras Morais e Convencionais em Crianças de Pré-Escola e do Primeiro Grau. Psicologia: Teoria e Pesquisa, v. 11, n. 3, p. 203-211, 1995. Disponível em https://revistaptp.unb.br/index.php/ptp/issue/view/46 Acesso em 31 de julho de 2016.

MENIN, M. S. S. Valores na Escola. Educação e Pesquisa, v.28, n.1, p. 91-102, 2002. Disponível em http://www.scielo.br/scielo.php?script=sci issuetoc\&pid=1517-970220020001\&lng=pt\&nrm=iso Acesso em 31 de julho de 2016.

PEREIRA, J. C. R. Análise de dados qualitativos: estratégias metodológicas para as ciências de saúde, humanas e sociais. São Paulo: Editora da Universidade de São Paulo, 1999.

PIAGET, J. O juízo moral na criança. 1. ed. São Paulo: Summus,1994. [originalmente publicado em 1932].

PIAGET, J. Os Procedimentos da Educação Moral. Trad. Maria Suzana de Stefano Menin. In: MACEDO, L. Cinco estudos de educação moral. São Paulo: Casa do Psicólogo, 1996. (originalmente publicado em 1930).

SILVA, I. A. et al. Considerações sobre a agressividade infantil. Olhares \& Trilhas, ano XVII, n. 21, p. 66-82, 2015. Disponível em http://www.seer.ufu.br/index.php/olharesetrilhas/issue/view/1299 Acesso em 31 de julho de 2016. 
TARDELI, D. A. O respeito na sala de aula. Petrópolis: Vozes, 2003.

TOGNETTA, L. R. P. Uma reflexão sobre as regras na escola que pretende formar para a autonomia e superar suas violências. In: TOGNETTA, L. R. P; LEME, M. I. S; VICENTIN, V. F. Quando os conflitos nos pertencem: uma reflexão sobre as regras e a intervenção nos conflitos na escola que pretende formar para a autonomia moral - volume 3. Campinas: Mercado de Letras, 2013, p. 47-82.

TOGNETTA, L. R. P.; VINHA, T. Quando a escola é democrática: um olhar sobre as regras e assembleias nas escolas. Campinas: Mercado de Letras, 2007.

TURIEL, E. The development of social knowledge. Cambridge: Cambridge University Press, 1983.

VINHA, T. P. O Educador e a Moralidade infantil: uma visão construtivista. 1. ed. Campinas: Mercado de Letras, Fapesp, 2000.

YIN, R. K. Estudo de caso: planejamento e método. 2. ed. Porto Alegre: Bookman, 2001. 